\title{
Effects of Vessel and Water Temperatures on Direct Injection in Internal Combustion Rankine Cycle Engines
}

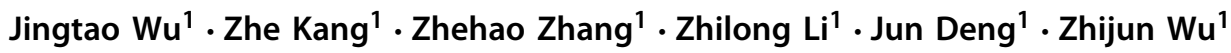

Received: 10 August 2018 / Accepted: 3 November 2018 / Published online: 4 December 2018

(c) The Author(s) 2018

\begin{abstract}
This study focused on the effects of vessel and water temperatures on direct injection in internal combustion Rankine cycle engines through experimental and numerical methods. First, a study was carried out with schlieren photography using a high-speed camera for simultaneous liquid-gas diagnoses. Water was directly injected into a constant-volume vessel that provided stable boundaries. We wrote a MATLAB program to calculate spray tip penetration and cone angle from the images. For the further extension of boundary conditions, a numerical model was established and calibrated in AVL-FIRE for the thorough analysis of injection characteristics. Both experimental and numerical results indicated that injection and vessel temperatures have different effects on spray tip penetration. An increase in injected water temperature leads to shorter spray tip penetration, while the spray tip penetration increases with increasing vessel temperature. However, increased injection and vessel temperatures can both decrease the spray cone angle. Moreover, the simulation results also suggested that heat conduction is a main factor in boosting evaporation under top dead center conditions. When the internal energy of water parcels surges, these parcels evaporate immediately. These results are helpful and crucial for internal combustion engines equipped with direct water injection technology.
\end{abstract}

Keywords Internal combustion Rankine cycle · Direct water injection - Water temperature · Vessel temperature

\section{Introduction}

Reducing environmental pollution is one of the most important research objectives for internal combustion engines. For this purpose, water injection technology has received much attention for several decades owing to its advanced effects, which not only reduce nitrogen oxide emissions and fuel consumption but also enhance thermal efficiency in both diesel and gasoline engines [1, 2]. However, inappropriate water injection is likely to quench the local flame, resulting in significant cycle-to-cycle variation and a substantial increase in hydrocarbon emissions [3]. Because of the advantages of water injection technology, many studies have been carried out to investigate the impacts of different water injection strategies on engine performance and emissions.

Zhijun Wu

zjwu@tongji.edu.cn

1 School of Automotive Studies, Tongji University, Shanghai 200092, China
Water injection technology has a positive effect on heat capacity in the cylinder, thereby lowering the peak combustion temperature. This technology [4] also leads to a significant gain in the knock-limiting ignition timing advance and decrease in the compression end temperature, as well as the temperature when the exhaust valve is open. Mahankali et al. [5] found that injecting water into the intake manifold also mitigated combustion knock, and they achieved an optimum combustion phasing based on the indicated fuel conversion efficiency with a water-to-fuel ratio of 0.6. Port water injection [6] could help engines operate under full load with a stoichiometric air-fuel ratio, and this resulted in up to a $5 \%$ improvement in net mean effective pressure and an improvement in thermal efficiency from 25 to $34 \%$ at $3000 \mathrm{rpm}$. Nicholls et al. [7] used inlet manifold water injection for control of nitrogen oxides, and experimental results showed that $10 \%$ water decreased nitrogen oxide emissions by $10-20 \%$.

Moreover, premature ignition of the air-fuel mixture can cause severe damage to turbocharged engines influenced by high intake temperatures. To control combustion and avoid detonation damage, water was also directly injected into an 
engine cylinder to cool the intake charge $[8,9]$. Kim et al. [8] considered that direct water injection showed the potential to advance spark timing and reduce brake-specific fuel consumption. Iwashiro et al. [10] studied direct water injection in a homogeneous charge compression ignition (HCCI) engine, and results showed that the indicated thermal efficiency was improved by about $2 \%$. In addition, the operation range was expanded from 460 to $700 \mathrm{kPa}$, which maintained a low level of nitrogen oxide emissions. Roumeliotis et al. [11] determined that water injection could help control ignition timing and slow down the heat release rate in an HCCI engine. In contrast, hydrocarbon emissions increased by $20 \%$ when the water-fuel ratio was 1:1. Taghavifar et al. [12] studied the effects of direct water injection on a hydrogen-diesel duel fuel engine and showed that a $15 \%$ water injection ratio at $60{ }^{\circ} \mathrm{C}$ produced the best performance and that a $5 \%$ water injection ratio at $27^{\circ} \mathrm{C}$ produced the lowest emissions. Recently, the condensed water injection concept [13] was proposed based on a stoichiometric combustion engine with a Miller cycle and cooled external exhaust gas recirculation. The results demonstrated a potential to increase efficiency from 3.3 to $3.8 \%$ in the region of minimum specific fuel consumption. The efficiency further improved by up to $16 \%$ at full-load operation.

In other studies, water injection dramatically improved the overall thermal efficiency in internal combustion engines by helping to control combustion temperature and acting as the working medium to push the piston after the water evaporated. Based on theoretical calculation, the overall system efficiency was predicted to be as high as $55 \%$ [14]. Wu et al. [15] conducted theoretical and experimental studies of implementing oxygen-fuel combustion in internal combustion engines with high-temperature and high-pressure water injection. The results showed that in spark ignition engines, added water could improve the thermal efficiency up to 56\% with zero emission by waste heat recovery [16]. As for compression ignition engines, Kang et al. [17] proved that water injection was more flexible than exhaust gas recirculation for controlling the combustion process in oxygen-fuel HCCI engines. The concept of this combustion mode is derived from the high-efficiency combustor developed by Clean Energy Systems, Inc., which is often referred as the internal combustion Rankine cycle (ICRC) [18], and its structure is shown in Fig. 1.

For a deep understanding on the effect of water injection on combustion and emissions characteristics, it is necessary to investigate the injection and spray characteristics of water. Iwashiro et al. [10] found that distributing the water spray in the squish region was an efficient way to mitigate detonation. Emberson et al. [20] examined the spray cone angle and spray tip penetration of water-diesel emulsions containing $10 \%$ and $20 \%$ water (by mass). Differences in the spray cone angle and spray tip penetration demonstrated that the

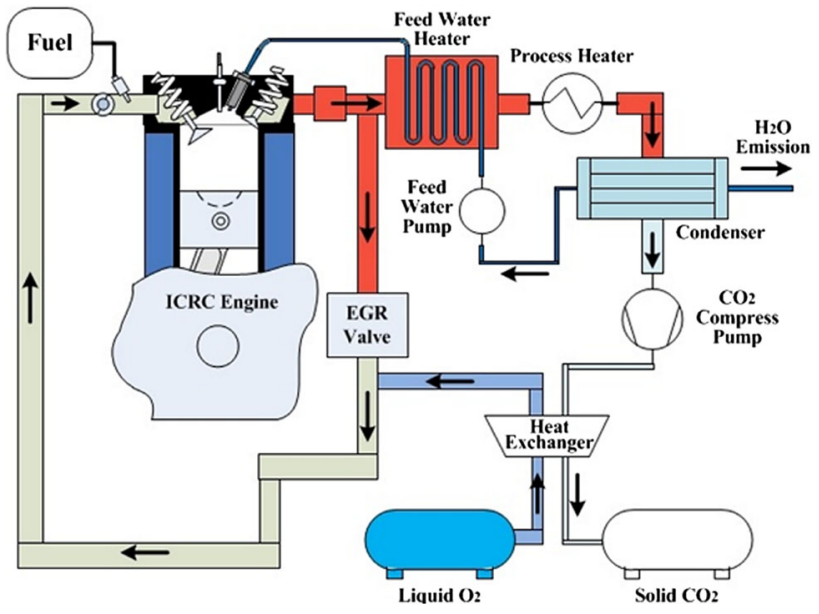

Fig. 1 Schematic of ICRC engine [19]

emulsification affected the injection process at a pressure of $50 \mathrm{MPa}$. Zhang et al. [21] studied the spray of water injection under high-temperature conditions using shadowgraphs, and results showed that for non-flash boiling sprays, liquid spray tip penetration had a positive correlation with the density of injection water, ambient density and injection pressure. Nishijima et al. [22] observed the water injection process in an optical engine and found that the water spray spread throughout the entire cylinder in only $1 \mathrm{~ms}$ under ambient temperature and pressure. Bedford et al. [23] simulated stratified direct water injection, which allowed the fuel-water percentage to be changed. They found that the liquid penetration increased approximately $35 \%$ when $23 \%$ of the fuel volume was replaced with water, due mostly to the increase in latent heat of vaporization. Van Vuuren et al. [24] photographed the water spray process of a urea injector with a high-speed camera and observed distinct differences when the temperature exceeded the atmospheric boiling point. Jeonghyun et al. [25] compared the spray characteristics of water and n-heptane in a port fuel injector. Their experimental results revealed that with increasing injection pressure, the injection quantity of water was about $21 \%$ higher than that of n-heptane. Bhagat et al. [3] observed a decrease in water spray tip penetration in a higher temperature air charge with a multi-hole gasoline direct injector.

However, few investigations have examined the characteristics of sprays utilized in ICRC engines, especially under top dead center (TDC) conditions. This study analyzed experimental points at different injected water and ambient temperatures in a vessel and validated a numerical model based on the experimental results for spray tip penetration. The simulation of the directed water spray process at TDC was evaluated. The results are intended to provide more details of basic water spray behavior in ICRC engines. 


\section{Experimental and Numerical Methods}

\subsection{Experimental Setup}

The experimental system consisted of an optical system, water injection system, control system, and data acquisition system. Figure 2 shows the optical setup of the schlieren test system. The light beam was created by an LED lamp and oriented toward a plane mirror (called plane mirror 1), which was placed at the focal point of a concave mirror (called concave mirror 1). Then, the light beam was reflected by the concave mirror and thus propagated in a parallel way. To receive and redirect the parallel light beam to a high-speed camera, a second concave mirror (called concave mirror 2 ) was placed approximately $3 \mathrm{~m}$ from concave mirror 1 , and another plane mirror (called plane mirror 2 ) was also positioned at the focal point of concave mirror 2.

Finally, a knife edge was placed between plane mirror 2 and the high-speed camera in the light path to record and visualize the density variations during the water spray process. In addition, a constant-volume vessel (CVV) with high ambient pressure and wide visualization windows was placed between the two concave mirrors. The CVV was a rectangular stainless-steel cube $(300 \mathrm{~mm} \times 300 \mathrm{~mm} \times 268 \mathrm{~mm})$ with a $\varphi 140-\mathrm{mm}$ circular glass window in each lateral face. In addition, electrical heaters and a thermocouple were added inside the CVV to control the inner vessel temperature. A light beam transmitted through one window propagated through the CVV and exited through the opposite window.

The main components of the water injection system involved a water injector, water rail, and air-fluid booster. A single-hole diesel injector was modified to inject water into the CVV, and the nozzle diameter was enlarged to $0.2 \mathrm{~mm}$. The water rail shown in Fig. 3 was an electronically controlled high-pressure water heater specifically designed and

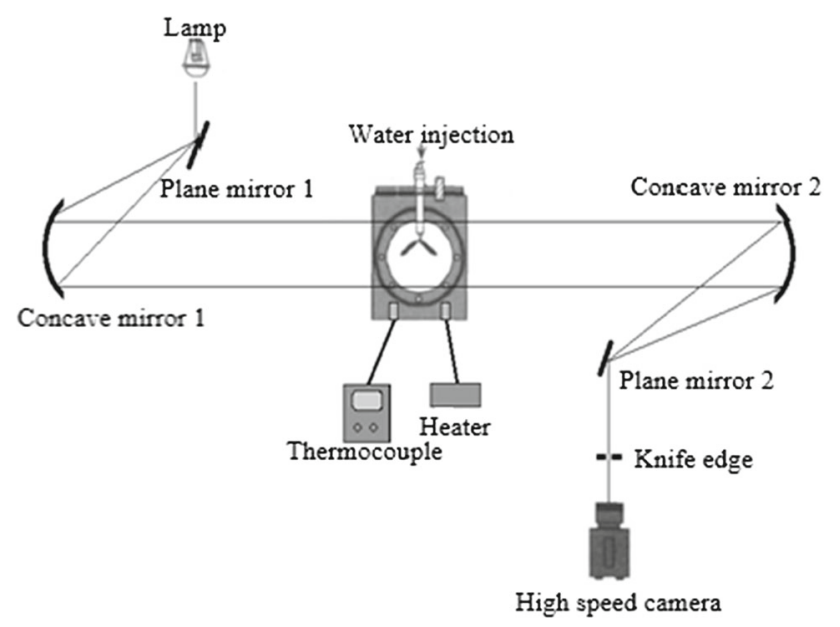

Fig. 2 Schlieren test system

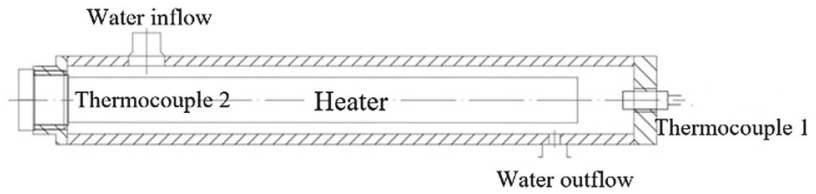

Fig. 3 Schematic of water rail

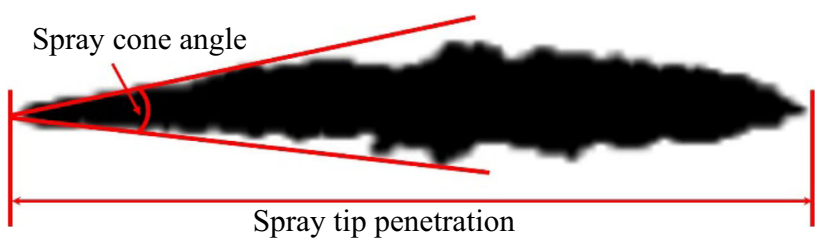

Fig. 4 Definition of spray characteristics (spray tip penetration and spray cone angle)

manufactured for this study. To control water temperature during heating process and avoid subcooled boiling of water near the rail's surface, two thermocouples were installed at both ends of the water rail near the rail inflow and outflow. An air-fluid booster was used as a water pump to ensure sufficient injection pressure. This approach was chosen to allow the injection of a large amount of water in a very short time. Finally, a Phantom v7.3 high-speed camera equipped with a Nikon lens with focal length of $52 \mathrm{~mm}$ was employed to capture the shape and change of the water spray in the CVV, and the imaging speed was 17,702 frames per second.

Due to the high sensitivity of the schlieren technique, the vapor phase boundary of the spray can be detected. As shown in Fig. 4, the spray tip penetration is defined as the distance, along the spray axis, between the nozzle tip and the leading edge of the spray. The spray angle is defined as the interval angle formed by the nozzle tip and two straight lines coinciding with the maximum outer edges of the spray [26].

To calculate the spray tip penetration and angle, we created a MATLAB program to process the raw schlieren images captured by the high-speed camera. Otsu's method was used to transform the raw images into gray images, as shown in Fig. 5. Figure 6 uses gray images to illustrate the spray process under the conditions of $20^{\circ} \mathrm{C}$ injected water temperature and $20^{\circ} \mathrm{C} \mathrm{CVV}$ ambient temperature. The experimental conditions are shown in Table 1.

\subsection{Numerical Simulation}

A spray is a complex three-dimensional physical event. The numerical simulation of water injection was carried out in the AVL-FIRE software for further investigation. Several equations were selected, including those for momentum, continuity, species transport, and k-epsilon turbulence. In this simulation, the KH-RT spray breakup model was used because it is suitable for the simulation of a high-pressure 

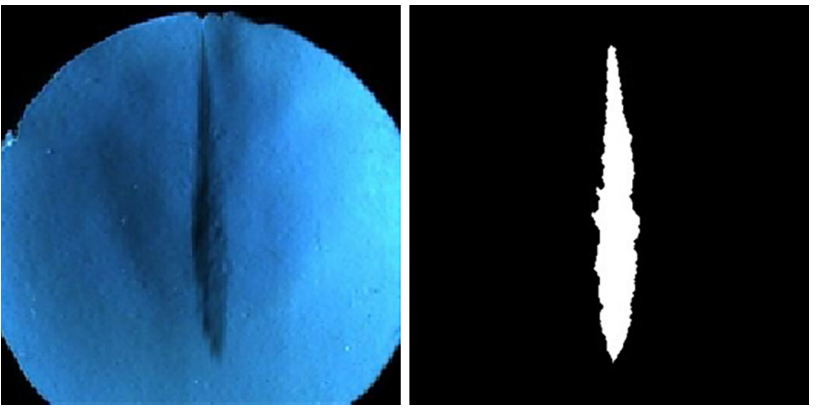

Fig. 5 Raw and gray images of spray

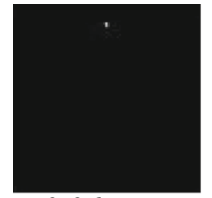

$0.06 \mathrm{~ms}$

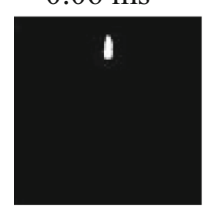

$0.30 \mathrm{~ms}$

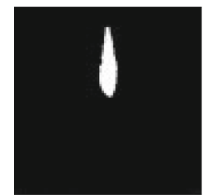

$0.54 \mathrm{~ms}$

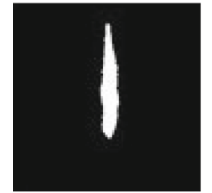

$0.78 \mathrm{~ms}$

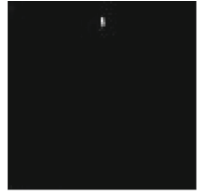

$0.12 \mathrm{~ms}$

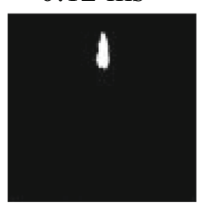

$0.36 \mathrm{~ms}$

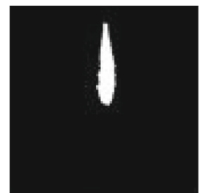
$0.60 \mathrm{~ms}$

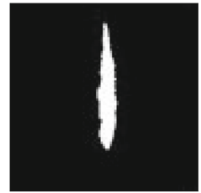

$0.84 \mathrm{~ms}$

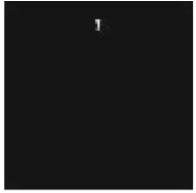

$0.18 \mathrm{~ms}$

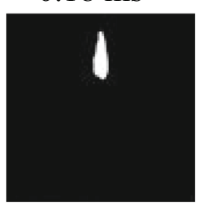

$0.42 \mathrm{~ms}$

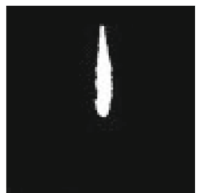

$0.66 \mathrm{~ms}$

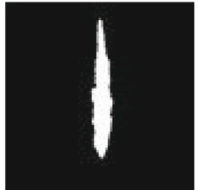

$0.90 \mathrm{~ms}$

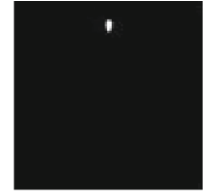

$0.24 \mathrm{~ms}$

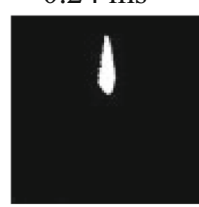

$0.48 \mathrm{~ms}$

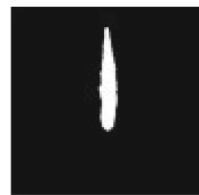

$0.72 \mathrm{~ms}$

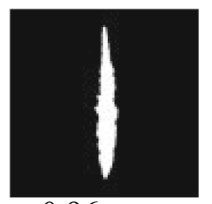

$0.96 \mathrm{~ms}$
Fig. 6 Gray images of spray (vessel conditions: $1 \mathrm{~atm}, 20^{\circ} \mathrm{C}$; injected water conditions: $20^{\circ} \mathrm{C}, 30 \mathrm{MPa}$ )

Table 1 Experimental temperature conditions

\begin{tabular}{lcc}
\hline Test points & $\begin{array}{l}\text { CVV temperature } \\
\left({ }^{\circ} \mathrm{C}\right)\end{array}$ & $\begin{array}{l}\text { Injected water } \\
\text { temperature }\left({ }^{\circ} \mathrm{C}\right)\end{array}$ \\
\hline BGT20-Water20 & 20 & 20 \\
BGT20-Water120 & 20 & 120 \\
BGT20-Water160 & 20 & 160 \\
BGT160-Water120 & 160 & 120 \\
BGT160-Water160 & 160 & 160 \\
BGT160-Water180 & 160 & 180 \\
\hline
\end{tabular}

solid cone spray. The fluid was set as compressible, and the other parameters were set at their default values.

As discussed above, although the CVV had a rectangular volume, results showed that the injected spray was mainly contained within a cylindrical space measuring $\varphi 40 \mathrm{~mm}$.

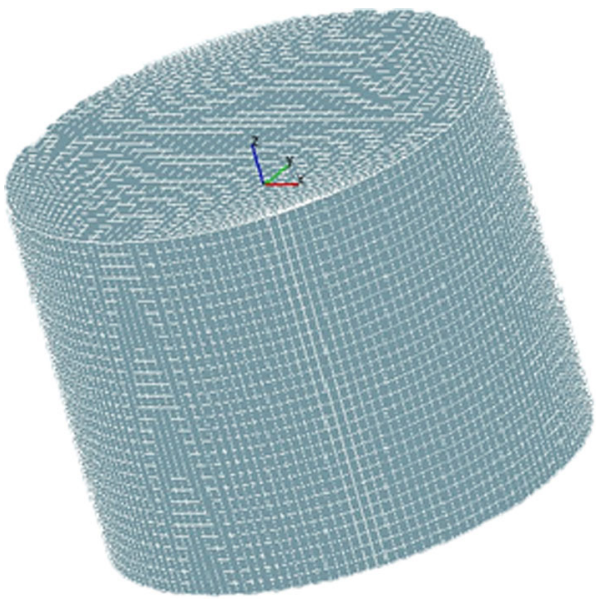

Fig. 7 Simulation geometry mesh

Thus, a cylindrical mesh was adopted for the spray simulation, and its radius was set as $150 \mathrm{~mm}$. The mesh density was a good compromise between too coarse a mesh, which would generate large side effects, and too fine a mesh, which would compromise calculation efficiency. The cylindrical mesh was built in ANSYS ICEM with 48,000 hexagonal cells, as shown in Fig. 7. To study the influence of injected water temperature on the spray and evaporation process, the following injected water temperatures were selected: $30^{\circ} \mathrm{C}, 50^{\circ} \mathrm{C}, 70^{\circ} \mathrm{C}, 90^{\circ} \mathrm{C}$, $110^{\circ} \mathrm{C}, 130^{\circ} \mathrm{C}$, and $160^{\circ} \mathrm{C}$, while the injection pressure was $30 \mathrm{MPa}$ and the $\mathrm{CVV}$ temperature was $20^{\circ} \mathrm{C}$. To study the influence of CVV temperature on spray and evaporation process, the same temperatures were selected for the CVV (with the same injection pressure and temperature).

\section{Results and Discussion}

\subsection{Experimental Results and Discussion}

To characterize the spray process, schlieren images of highpressure direct water injection were analyzed by calculating time-dependent spray tip penetration, spray cone angle, and mean spray speed. Results under $30 \mathrm{MPa}$ injection pressure are presented here at the condition of $1 \mathrm{~atm}$ ambient pressure. The experiments with CVV temperatures under $100{ }^{\circ} \mathrm{C}$ were considered as low-temperature tests, and the high-temperature tests were those above $100{ }^{\circ} \mathrm{C}$.

Macroscopic experimental results are shown in Fig. 8 at the experimental conditions of $1 \mathrm{~atm}$ ambient pressure and $30 \mathrm{MPa}$ injection pressure. As shown in Fig. 8a, the spray tip penetration length varied with time at different ambient and injected water temperatures. An increase in injected water temperature led to shorter spray tip penetration, while increasing CVV temperature tended to increase spray tip penetration. Figure $8 \mathrm{~b}$ shows the spray tip penetration length was 

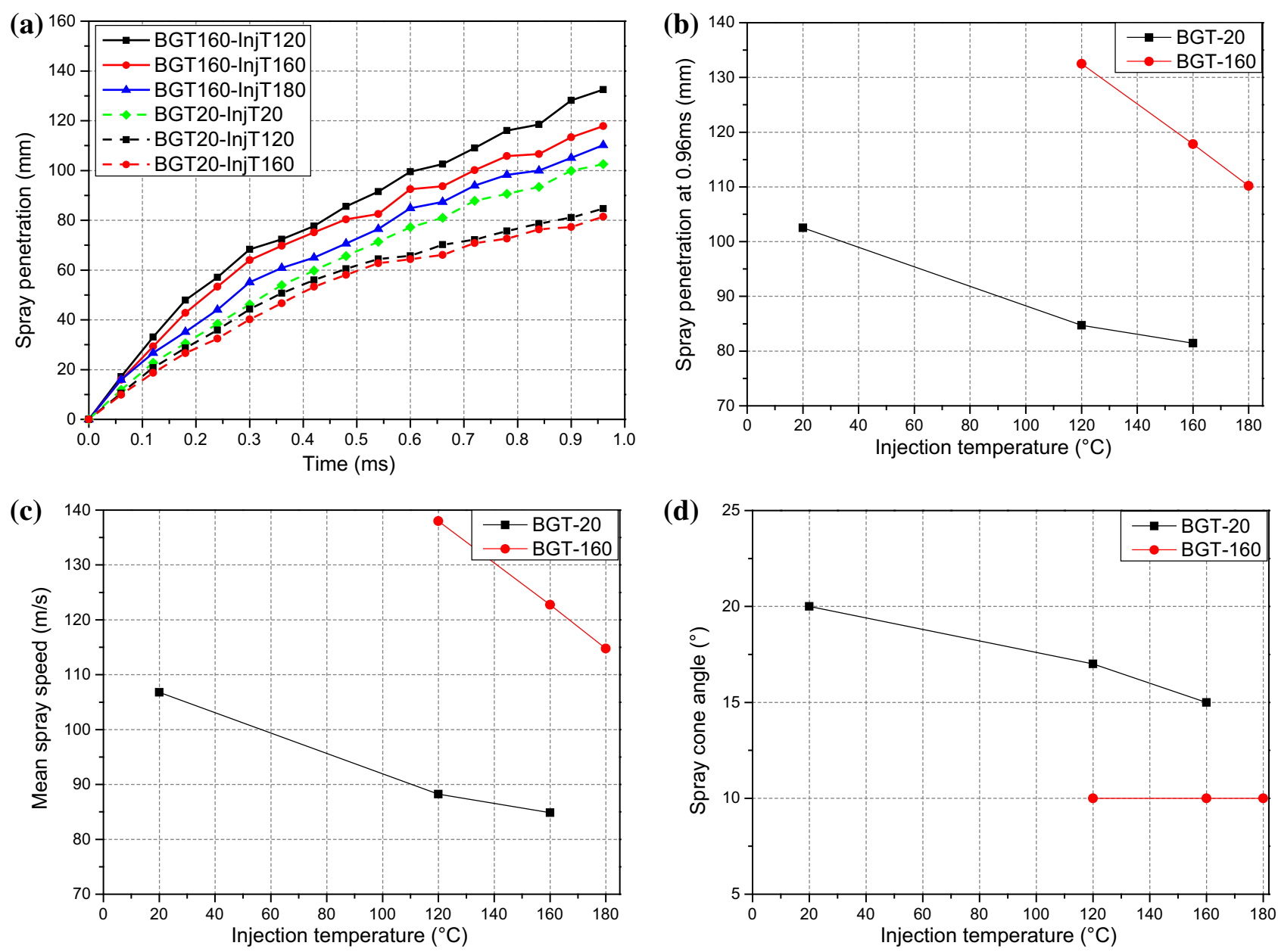

Fig. 8 Macroscopic experimental results (vessel pressure $=1 \mathrm{~atm}$; injection pressure $=30 \mathrm{MPa}$ ). a Spray penetration, $\mathbf{b}$ spray penetration at $0.96 \mathrm{~ms}$, c mean spray speed, and $\mathbf{d}$ spray cone angle

$0.96 \mathrm{~ms}$ after the start of injection. This length decreased from 102.53 to $81.45 \mathrm{~mm}$ when the injected water temperature increased from 20 to $160^{\circ} \mathrm{C}$ with the same CVV temperature $\left(20^{\circ} \mathrm{C}\right)$. However, as the CVV temperature increased from 20 to $160^{\circ} \mathrm{C}$, the length increased from 81.452 to $117.83 \mathrm{~mm}$ with the same injected water temperature $\left(160^{\circ} \mathrm{C}\right.$.) As seen in Fig. 8c, the mean spray speed was calculated with the raw schlieren images. The results suggest that increased injected water temperature tended to decrease mean spray speed. A difference of $21.95 \mathrm{~m} / \mathrm{s}$ was found between injected water temperatures at $20^{\circ} \mathrm{C}$ and $160{ }^{\circ} \mathrm{C}$ with the same $\mathrm{CVV}$ temperature of $20{ }^{\circ} \mathrm{C}$. The mean spray speed increased with increasing CVV temperature, and there was a difference of $53.16 \mathrm{~m} / \mathrm{s}$ between CVV temperatures at $20^{\circ} \mathrm{C}$ and $160{ }^{\circ} \mathrm{C}$ with the injected water temperature at $120^{\circ} \mathrm{C}$. In Fig. 8d, both injection and CVV temperatures have interesting impacts on spray cone angle. On the one hand, in the low-temperature range, the spray cone angle became smaller dramatically, decreasing from $20^{\circ}$ to $15^{\circ}$ with increasing injected water temperature. The evaporation rate clearly increased, and the effect of spray evaporation improved markedly. Nevertheless, in the high-temperature test group, there was little change in spray cone angle as a result of the limited effect of increased injected water temperature on increased evaporation rate. Therefore, the spray cone angle tended to be stable. On the other hand, the spray cone angle decreased with increasing CVV temperature and remained roughly unchanged at higher CVV temperatures.

Viewed in another way, evaporation is a type of vaporization that occurs on the surface of a liquid as it changes into a gaseous phase before reaching its boiling point [26]. When the molecules of the liquid collide, they transfer energy to each other based on how they collide. When a molecule near the surface absorbs enough energy to overcome the vapor pressure, it will escape and enter the surrounding air as a gas [27]. The internal energy of water molecules increases because of the increase in injected water temperature, and the heat conduction between the ambient air and the liquid water molecules increases when the CVV temperature increases. These two phenomena both lead to sufficient 

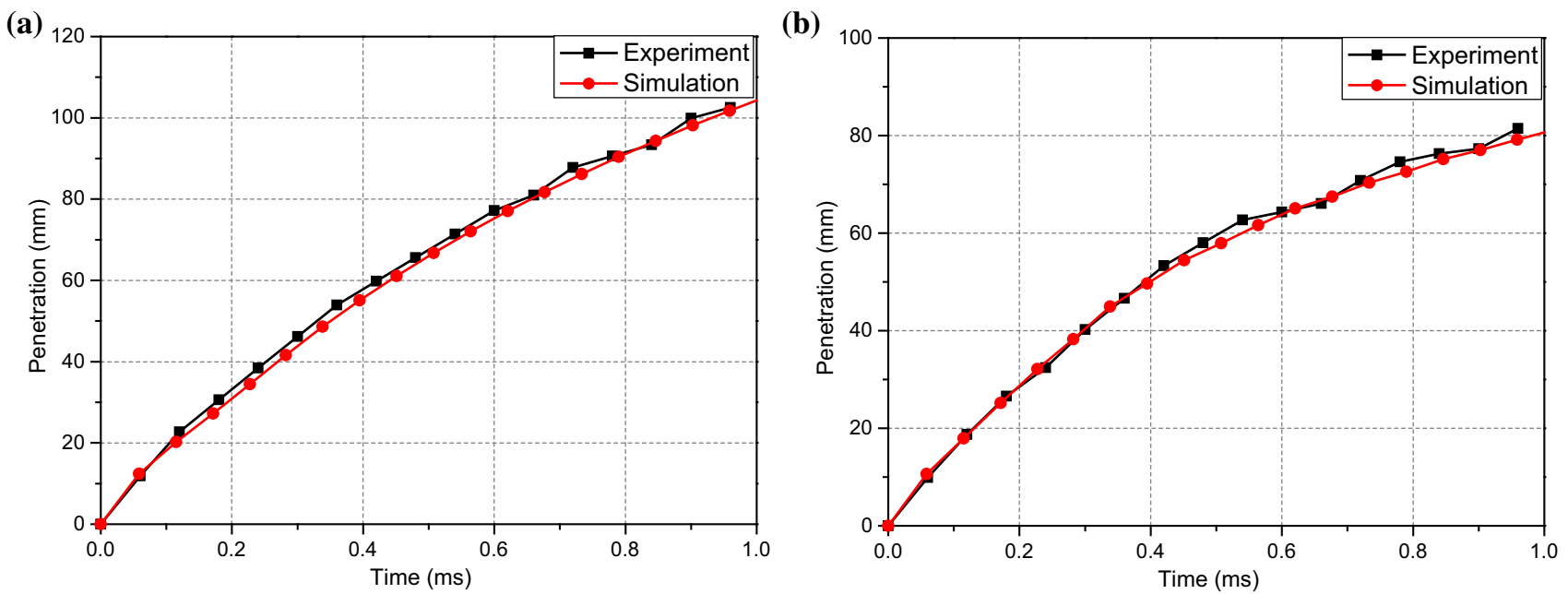

Fig. 9 Validation of spray tip penetration in numerical model. a BGT20-InjT20 and b BGT20-InjT160

energy in the water molecules. Thus, they overcome the surface tension and viscous force, separate from the liquid surface, and enter the surrounding air as a gas [28]. As a result, the spray cone angle decreases when the evaporation rate increases. However, the evaporation process is also influenced by the interface area between ambient air and liquid water. In one respect, the water parcels only evaporate layer by layer through the interface. In another respect, the heat conduction between ambient air and liquid water molecules is also limited by the interface area. The process of spray and evaporation reaches a dynamic equilibrium, so there is little change in the spray cone angle when both the injected water temperature and CVV temperature are high enough.

\subsection{Numerical Results and Discussion}

To further extend the boundary conditions, a numerical model was established and calibrated in AVL-FIRE, which was able to provide extensive data for the analysis of spray and evaporation processes.

First, to numerically reproduce the experimental water injection process, the spray tip penetration was validated at $20{ }^{\circ} \mathrm{C}$ and $160{ }^{\circ} \mathrm{C}$ ambient conditions. Second, to study the influence of injected water temperature on spray and evaporation processes, we adopted the injected water temperatures as $30{ }^{\circ} \mathrm{C}, 50{ }^{\circ} \mathrm{C}, 70{ }^{\circ} \mathrm{C}, 90^{\circ} \mathrm{C}, 110^{\circ} \mathrm{C}, 130^{\circ} \mathrm{C}$, and $160{ }^{\circ} \mathrm{C}$, a CVV temperature as $20^{\circ} \mathrm{C}$, and an injection pressure as $30 \mathrm{MPa}$. Third, to study the influence of CVV temperature on spray and evaporation processes, we also adopted the CVV temperatures as $30{ }^{\circ} \mathrm{C}, 50{ }^{\circ} \mathrm{C}, 70{ }^{\circ} \mathrm{C}, 90^{\circ} \mathrm{C}, 110^{\circ} \mathrm{C}, 130{ }^{\circ} \mathrm{C}$, and $160{ }^{\circ} \mathrm{C}$, an injected water temperature as $20^{\circ} \mathrm{C}$, and an injection pressure as $30 \mathrm{MPa}$. Finally, the influence of TDC conditions on spray and evaporation processes was evaluated.

Before performing further simulation, the spray breakup models and parameters for the spray simulation were selected and validated against the experimental results. In the validation, the simulated initial conditions were identical to the experimental conditions. The simulation time was set as $3 \mathrm{~ms}$, which corresponded to the duration of the experiments, although the spray was only visible for $1 \mathrm{~ms}$. Two cases, one from a high CVV temperature and the other from a low CVV temperature, were selected and validated. Figure 9 presents the comparison of spray tip penetration between the simulation and experiment. The correlation coefficients of the low-temperature and high-temperature cases were 0.986 and 0.962 , respectively. Therefore, it was reasonable to conclude that there was satisfactory coincidence between the experimental and simulated results.

\subsubsection{Influence of Injected Water Temperature on Spray Characteristics}

Figure 10 presents the simulated results of the influence of injected water temperature on spray and evaporation processes. The CVV temperature was $20{ }^{\circ} \mathrm{C}$ and injection pressure $30 \mathrm{MPa}$. Simulated spray tip penetration was determined based on the liquid mass in the whole domain.

It can be seen in Fig. 10a that the increase in injected water temperature led to decreasing spray tip penetration length. Specifically, $3 \mathrm{~ms}$ after the start of injection, the spray tip penetration at $160{ }^{\circ} \mathrm{C}$ injected water temperature was $31.52 \mathrm{~mm}$, shorter than that at $30^{\circ} \mathrm{C}$. This trend agreed with the experimental results. As shown in Fig. 10b, the mean Sauter diameter was calculated by the local droplet size at each time step. It dropped from 54.55 to $32.51 \mu \mathrm{m}$ when the injected water temperature increased from 30 to $160{ }^{\circ} \mathrm{C}$. As to the variation in penetration, this can be explained by the fact that higher injected water temperature causes higher internal energy in water molecules. This leads to the water molecules on the interface between spray liquid and ambi- 

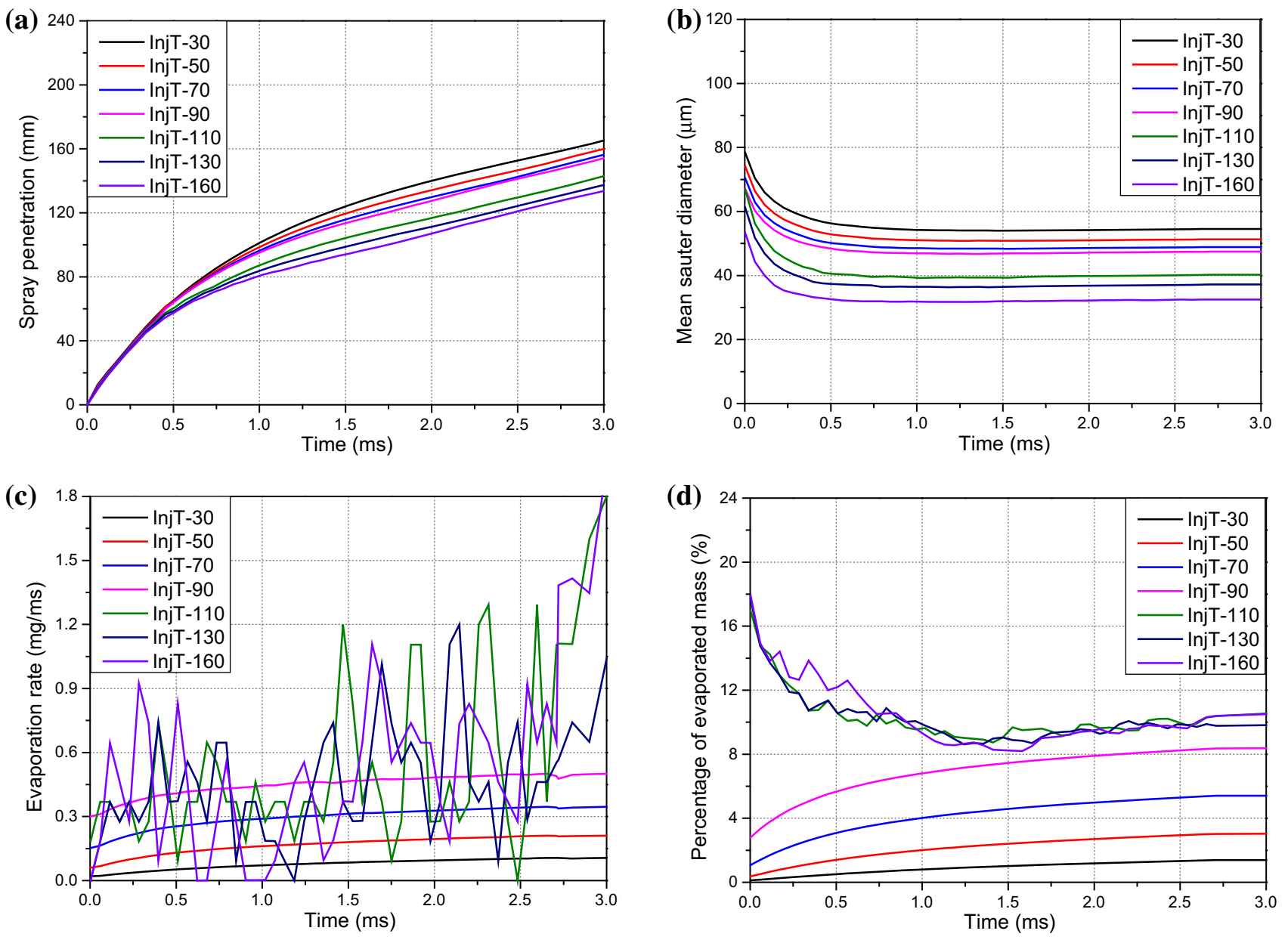

Fig. 10 Influence of injected water temperature on spray and evaporation process. a Spray penetration, $\mathbf{b}$ mean Sauter diameter, $\mathbf{c}$ evaporation rate, and $\mathbf{d}$ percentage of evaporated mass

ent air overcoming the surface tension and viscous force, stretching, breaking up, and separating from the liquid surface. As a consequence, the atomization and vaporization speed up, producing a shorter spray tip penetration length and a smaller mean Sauter diameter as the injected water temperature increases. It is difficult to measure evaporated mass experimentally, but it is crucial for the dynamic equilibrium of direct water injection, so it is certainly worth investigating the evaporation process by numerical simulation. To better understand the evolution of the evaporation, the evaporation rate, which is evaporated mass differentiated by time, was calculated, and the results are shown in Fig. 10c. At the same time, the percentage of evaporated mass was also calculated, which is evaporated mass divided by liquid injection mass at each time step, and these results are shown in Fig. 10d. The evaporation rate increased with increasing injected water temperature when the injected water temperature was below $100{ }^{\circ} \mathrm{C}$, but it remained almost stable when the injected water temperature was above $100^{\circ} \mathrm{C}$. Similarly, the percentage of evaporated mass increased dramatically from $1.8 \%$ at $30^{\circ} \mathrm{C}$ to $8.2 \%$ at $90^{\circ} \mathrm{C}$ with the increase in injected water temperature. However, there was an opposite trend when the injected water temperature was above $100{ }^{\circ} \mathrm{C}$ : A lot of water evaporated immediately at the exit of the nozzle, and it plateaued at $10 \%$ after $2 \mathrm{~ms}$. As stated above, when the injected water temperature was below $100^{\circ} \mathrm{C}$, the internal energy increased as the injected water temperature increased, and the evaporation rate also increased the percentage of evaporated mass increased. However, when the injected water temperature was above $100{ }^{\circ} \mathrm{C}$, the fluctuation in the evaporation rate was very small. This can be explained by the fact that when the injected water temperature is above saturated steam temperature in the ambient environment, vaporization occurs violently in the initial stage of the spray process and forms a lot of bubbles. The bubbles grow and break, generating significant energy that reduces the time of spray atomization effectively. With the development of the spray process, the evaporation rate is almost the same, and the percentage of evaporated mass drops slowly and eventually stabilizes. 

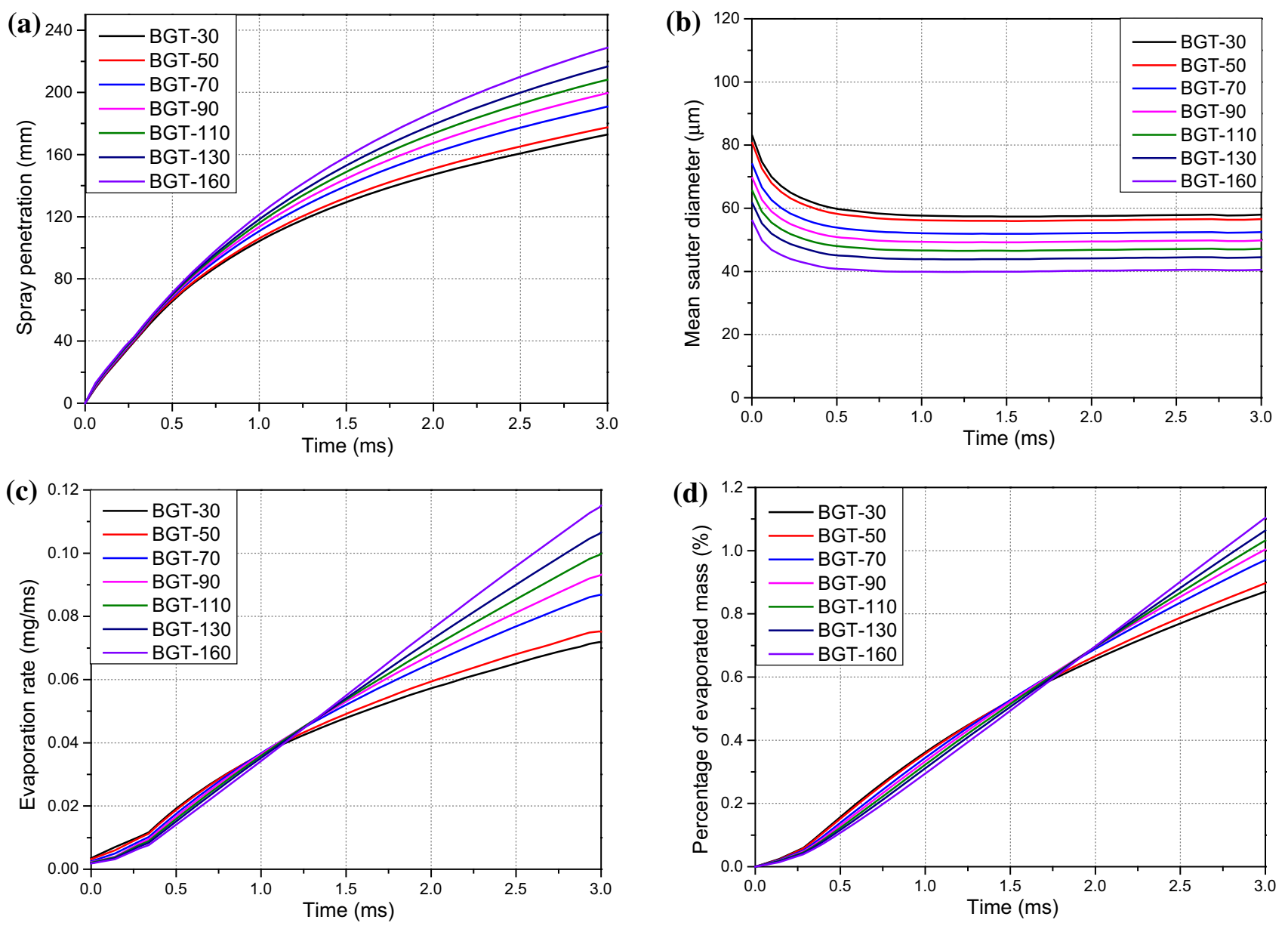

Fig. 11 Influence of vessel temperature on spray and evaporation processes. a Spray penetration, $\mathbf{b}$ mean Sauter diameter, $\mathbf{c}$ evaporation rate, and d percentage of evaporated mass

\subsubsection{Influence of Vessel Temperature on Spray Characteristics}

The simulations shown in Fig. 11 indicate the influence of CVV temperature on spray and evaporation processes. The injected water temperature was $20^{\circ} \mathrm{C}$ and the injection pressure was $30 \mathrm{MPa}$. As shown in Fig. 11a, the spray tip penetration length increased with increasing CVV temperature. Simulation results showed that the spray tip penetration was $55.89 \mathrm{~mm}$ in a $160{ }^{\circ} \mathrm{C} \mathrm{CVV}$, longer than that in a $30^{\circ} \mathrm{C} \mathrm{CVV}$. As shown in Fig. 11b, the mean Sauter diameter decreased from 57.96 to $40.54 \mu \mathrm{m}$ as the CVV temperature increased from 30 to $160{ }^{\circ} \mathrm{C}$, indicating that increased $\mathrm{CVV}$ temperature boosts atomization. The evaporation rate increased with increasing CVV temperature because the heat conduction between ambient air and liquid water molecules increases, resulting in shorter spray tip penetration. However, air density also decreases, which contributes to an increase in spray tip penetration. These two processes compete with each other. The results clearly show that the decrease in air density seemed to be more dominant than the increase in evaporation rate. Therefore, the spray tip penetration length decreased when the CVV temperature was below $160^{\circ} \mathrm{C}$. As is seen in Fig. 7c, the CVV temperature in the range from 30 to $160{ }^{\circ} \mathrm{C}$ had little influence on the evaporation rate. Similarly, there was also little influence on the percentage of evaporated mass, which is shown in Fig. 11d. This can be explained by the duration of the spray process being too short to benefit from a significant change in the heat conduction between ambient air and liquid water molecules. Thus, the percentage of evaporated mass varied from 0.86 to $1.12 \%$ when the CVV temperature ranged from 30 to $160^{\circ} \mathrm{C}$.

\subsubsection{Influence of Top Dead Center Conditions on Spray Characteristics}

As explained above, the previous sets of simulations were performed only under initial conditions, which were identical to the experimental conditions. However, it was meaningful to analyze the spray process under conditions similar to those in operating engines. To predict spray characteristics in ICRC engines, additional simulations were carried out to mimic the 

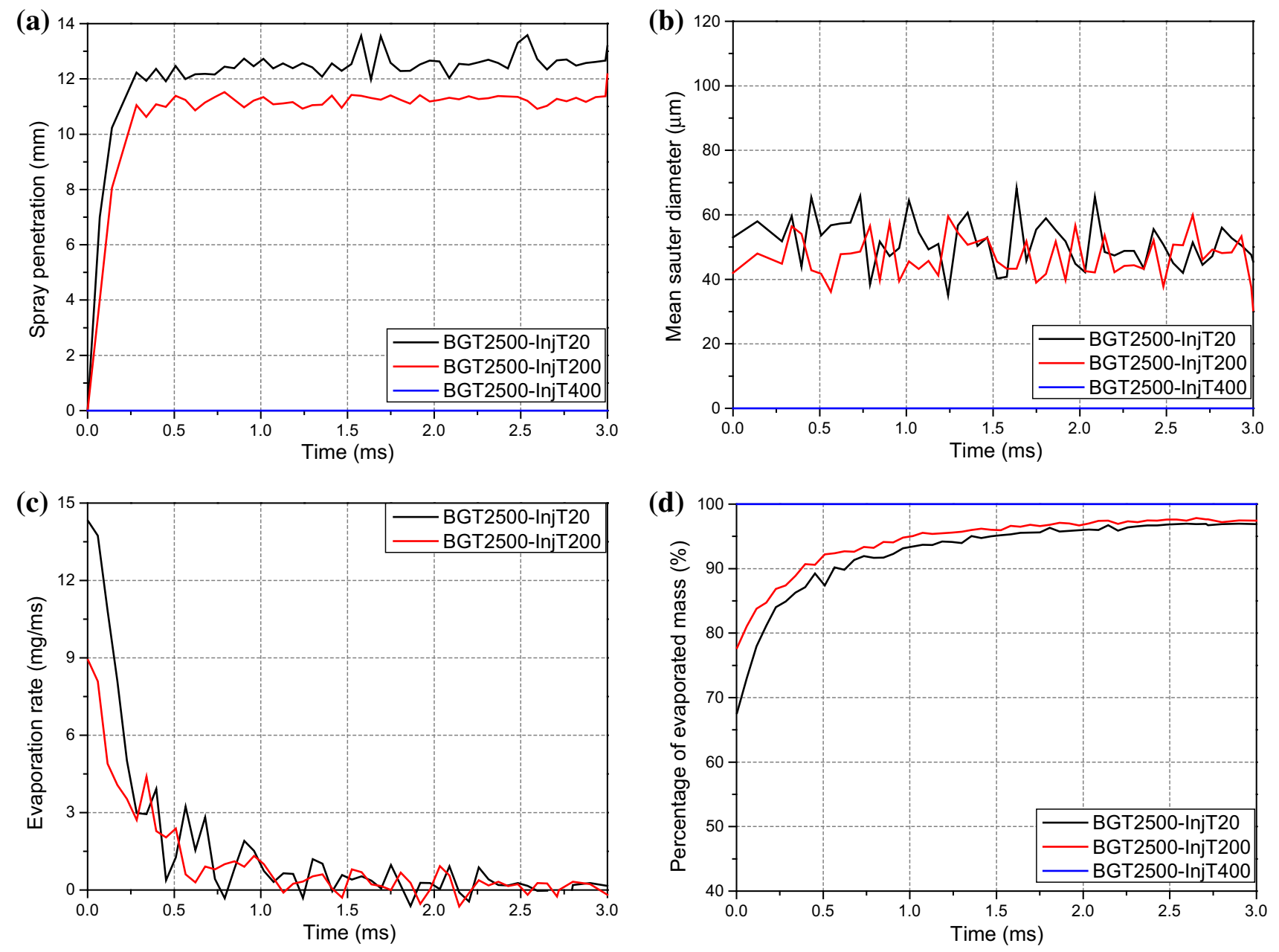

Fig. 12 Influence of TDC conditions on spray and evaporation processes. a Spray penetration, $\mathbf{b}$ mean Sauter diameter, $\mathbf{c}$ evaporation rate, and $\mathbf{d}$ percentage of evaporated mass

environment of an engine under full load at $1500 \mathrm{rpm}$ [29]. To reproduce TDC conditions, we specified the in-cylinder pressure as $5 \mathrm{MPa}$, temperature as $2200{ }^{\circ} \mathrm{C}$, and air density as $7.0424 \mathrm{~kg} / \mathrm{m}^{3}$, which corresponds to the density of dry air at this pressure and temperature.

The simulation results are shown in Fig. 12. The spray tip penetration length was clearly much shorter than that under the experimental conditions. As shown in Fig. 12a, for relatively low injected water temperatures (from 20 to $200{ }^{\circ} \mathrm{C}$ ), the injected water temperature had little influence on the spray tip penetration because the CVV temperature was so high that the evaporation rate increased dramatically. The heat conduction between ambient air and liquid water molecules increased, resulting in extremely short spray tip penetration. The spray tip penetration was about $12 \mathrm{~mm}$ at a $20{ }^{\circ} \mathrm{C}$ injected water temperature and around $11 \mathrm{~mm}$ at a $200{ }^{\circ} \mathrm{C}$ injected water temperature. However, the water fully evaporated instantaneously at an injected water temperature of $400{ }^{\circ} \mathrm{C}$. Figure $12 \mathrm{~b}$ gives the average droplet size under TDC conditions, and it shows a highly unstable performance between 40 and $60 \mu \mathrm{m}$. Figure $12 \mathrm{c}$ shows that there was a little difference in evaporation rate, and Fig. 12d suggests that the injected water temperature had little influence on the percentage of evaporated mass at relatively low injected water temperatures (from 20 to $200{ }^{\circ} \mathrm{C}$ ), although higher temperature correlated with a higher percentage of evaporated mass. However, at relatively high injected water temperatures $\left(400{ }^{\circ} \mathrm{C}\right)$, the water evaporated instantaneously. The simulation results suggest that heat conduction between ambient air and liquid water molecules is the main factor for boosting the evaporation process at TDC conditions. When the internal energy of the liquid water molecules increased, the liquid water molecules evaporated immediately.

\section{Conclusions}

This work investigated the influences of CVV and injected water temperatures on direct water injection by experimentally analyzing six different temperature conditions. In 
addition, a numerical model has been built and validated using the experimental results for spray tip penetration. The experimental equipment restricted our ability to conduct the experiment at the high temperatures and pressures related to TDC in an engine cylinder. Therefore, we used simulations to understand water spray processes at TDC conditions, which can provide more details for predictive analysis. The results can be summarized as follows:

1. Both experimental and simulated results showed that an increase in injected water temperature leads to shorter spray tip penetration and smaller spray cone angle. In addition, the simulation results indicated that the evaporation rate increased dramatically, by $6.4 \%$, when the injected water temperature increased from 30 to $110^{\circ} \mathrm{C}$, but it remained roughly unchanged, at around $10 \%$, when the injected water temperature continuously increased above $110^{\circ} \mathrm{C}$.

2. The results indicated that the spray tip penetration length increases with increasing CVV temperature, but the spray cone angle decreases. The CVV temperature has slight influence on the evaporation rate and percentage of evaporated mass. The evaporated mass rate increased slightly, by $1.6 \%$, as the CVV temperature increased from 30 to $160{ }^{\circ} \mathrm{C}$.

3. According to the simulation results, it can be predicted that heat conduction between ambient air and liquid water molecules is a main factor in boosting the evaporation process under TDC conditions. When the internal energy of liquid water molecules increases, these water molecules evaporate immediately.

Acknowledgements The authors gratefully acknowledge the financial support provided by National Natural Science Foundation of China (Nos. 91441125 and 51076118).

Open Access This article is distributed under the terms of the Creative Commons Attribution 4.0 International License (http://creativecomm ons.org/licenses/by/4.0/), which permits unrestricted use, distribution, and reproduction in any medium, provided you give appropriate credit to the original author(s) and the source, provide a link to the Creative Commons license, and indicate if changes were made.

\section{References}

1. Hountalas, D., Mavropoulos, G., Zannis, T.: Comparative evaluation of EGR, intake water addition and fuel-water emulsion as $\mathrm{NO}_{\mathrm{x}}$ reduction techniques for heavy duty diesel engines. SAE International Congress \& Exhibition, Society of Automotive Engineers, pp. 509-510 (2007)

2. Miyamoto, N., Ogawa, H., Wang, J., et al.: Significant $\mathrm{NO}_{\mathrm{x}}$ reductions with direct water injection into the sub-chamber of an IDI diesel engine. In: International Congress \& Exposition (1995)

3. Bhagat, M., Cung, K., Johnson, J., et al.: Experimental and numerical study of water spray injection at engine-relevant conditions. In: SAE 2013 World Congress \& Exhibition (2013)
4. Netzer, C., Franken, T., Seidel, L., et al.: Numerical analysis of the impact of water injection on combustion and thermodynamics in a gasoline engine using detailed chemistry. In: WCX World Congress Experience (2018)

5. Miganakallu, N., Naber, J.D., Rao, S., et al.: Experimental investigation of water injection technique in gasoline direct injection engine. In: ASME 2017 Internal Combustion Engine Division Fall Technical Conference, pp. V001T03A013 (2017)

6. Worm, J., Naber, J., Duncan, J., et al.: Water injection as an enabler for increased efficiency at high-load in a direct injected, boosted, SI engine. SAE Int. J. Engines 10(3), 951-958 (2017)

7. Nicholls, J.E., Ei-Messiri, I.A., Newhali, H.K.: Inlet manifold water injection for control of nitrogen oxides: theory and experiment. SAE Trans. 78(9), 70 (1969)

8. Kim, J., Park, H., Bae, C., et al.: Effects of water direct injection on the torque enhancement and fuel consumption reduction of a gasoline engine under high-load conditions. Int. J. Engine Res. 17(7), 795-808 (2016)

9. Berni, F., Breda, S., Lugli, M., et al.: A numerical investigation on the potentials of water injection to increase knock resistance and reduce fuel consumption in highly downsized GDI engines. Energy Procedia 81, 826-835 (2015)

10. Iwashiro, Y., Tsurushima, T., Asaumi, Y., et al.: Fuel consumption improvement and operation range expansion in $\mathrm{HCCI}$ with direct water injection. Trans. Soc. Automot. Eng. Jpn. 33, 103-107 (2002)

11. Roumeliotis, I., Mathioudakis, K.: Evaluation of water injection effect on compressor and engine performance and operability. Appl. Energy 87(4), 1207-1216 (2010)

12. Taghavifar, H., Anvari, S., Parvishi, A.: Benchmarking of water injection in a hydrogen-fueled diesel engine to reduce emissions. Int. J. Hydrog. Energy 42(16), 11962-11975 (2017)

13. Hoppe, F., Thewes, M., Baumgarten, H., et al.: Water injection for gasoline engines: potentials, challenges, and solutions. Int. J. Engine Res. 17(1), 86-96 (2016)

14. Osman, A.: Feasibility study of a novel combustion cycle involving oxygen and water, SAE International (2009)

15. Wu, Z., Fu, L., Gao, Y., et al.: Thermal efficiency boundary analysis of an internal combustion Rankine cycle engine. Energy 94, 38-49 (2016)

16. Wu, Z.J., Yu, X., Fu, L.Z., et al.: A high efficiency oxyfuel internal combustion engine cycle with water direct injection for waste heat recovery. Energy 70(3), 110-120 (2014)

17. Kang, Z., Wu, Z.J., Zhang, Z.H., et al.: Study of the combustion characteristics of a HCCI engine coupled with oxy-fuel combustion mode. SAE Int. J. Engines 10(3), 908-916 (2017)

18. Bilger, R.W., Wu, Z.J.: Carbon capture for automobiles using internal combustion rankine cycle engines. J. Eng. Gas Turbines Power 131(3), 034502 (2009)

19. Yu, X., Wu, Z., Wang, C., et al.: Study of the combustion and emission characteristics of a quasi ICRC engine under different engine loads, SAE International (2014)

20. Emberson, D.R., Ihracska, B., Imran, S., et al.: Optical characterization of diesel and water emulsion fuel injection sprays using shadowgraphy. Fuel 172, 253-262 (2016)

21. Zhang, Z., Kang, Z., Fu, L., et al.: Experiment on spray characteristics of water injection in thermo-atmosphere. Trans. CSICE 35(5), 443-451 (2017)

22. Nishijima, Y., Asaumi, Y., Aoyagi, Y.: Impingement spray system with direct water injection for premixed lean diesel combustion control, SAE International (2002)

23. Bedford, F., Rutland, C., Dittrich, P., et al.: Effects of direct water injection on DI diesel engine combustion, SAE International (2000)

24. van Vuuren, N., Qin, J.: High speed video measurements with water of a planar laser illuminated heated tip urea injector spray, SAE International (2013) 
25. Jeonghyun, P., Kyung-hwan, L., Suhan, P.: Comparison of injection and spray characteristics of water and n-heptane in a PFI injector. J. ILASS-Korea 2017, 113 (2017)

26. Park, S.H., Kim, H.J., Suh, H.K., et al.: Atomization and spray characteristics of bioethanol and bioethanol blended gasoline fuel injected through a direct injection gasoline injector. Int. J. Heat Fluid Flow 30(6), 1183-1192 (2009)
27. Aktershev, S.P., Ovchinnikov, V.V.: Modeling of the vaporization front on a heater surface. J. Eng. Thermophys. 20(1), 77-88 (2011)

28. Faeth, G.M., Hsiang, L.P., Wu, P.K.: Structure and breakup properties of sprays. Int. J. Multiph. Flow 21(12), 99-127 (1995)

29. Kang, Z., Fu, L., Deng, J., et al.: Experimental study of knock control in an internal combustion rankine cycle engine. J. Tongji Univ. (Nat. Sci.) (7), 1030-1036 (2017) 